\title{
Patrimonio vernáculo y acupuntura rural arquitectónica en Oaxaca. Una revisión crítica al proceso endógeno del Centro Cultural Comunitario en Teotitlán del Valle
}

\author{
Fabricio Lázaro Villaverde \\ Juan Manuel Gastéllum Alvarado \\ Facultad de Arquitectura C.U. \\ Universidad Autónoma Benito Juárez de Oaxaca
}

\section{Resumen}

Teotitlán del Valle es una población de origen zapoteca del estado de Oaxaca que a lo largo de su historia (desde la época prehispánica hasta la actualidad) ha mantenido sus tradiciones y costumbres, siendo el diseño de la ciudad una parte toral para ello, pues su origen está basado en su orientación arqueo-astronómica y la traza de origen prehispánico ha mantenido su funcionalidad. Aunque ha sufrido algunos cambios, estos integraron el conjunto religioso-político y comercial. En este artículo se analiza de manera crítica la inclusión en la comunidad del proyecto Centro Cultural Comunitario (cCC) desde diferentes etapas (diseño, construcción y funcionamiento actual), detallando los problemas de entendimiento cultural existentes desde el principio, la incertidumbre durante la construcción y la falta de resolución a problemas esenciales para su funcionamiento, mostrando así el soslayo del valor patrimonial de la región en aras de construir un ícono arquitectónico.

Palabras clave: Patrimonio vernáculo, acupuntura rural arquitectónica, Teotitlán del Valle, Centro Cultural Comunitario, Oaxaca.

\section{Abstract}

Teotitlán del Valle is a town of zapotec origin in the state of Oaxaca that throughout its history (from pre-Hispanic times to the present) has maintained its traditions and customs, the design of the city being a key factor, as its origin is based on its archaeo-astronomical orientation and the pre-Hispanic layout has maintained its function- 
ality. Although it has undergone some changes, these integrated the religious-political and commercial set. This article critically analyzes the inclusion in the community of the Community Cultural Center (CCC) project from different stages (design, construction, and current operation), detailing the problems of cultural understanding from the beginning, the uncertainty during construction and the lack of resolution to essential problems for its operation, thus showing the neglect of the heritage value of the region to build an architectural icon.

Key words: Vernacular heritage, architectural rural acupuncture, Teotitlán del Valle, Community Cultural Center, Oaxaca.

\section{Teotitlán del Valle, un enclave dentro del eje patrimonial oriente}

Imagen 1: Esquema del corredor cultural oriente. Autor: Juan Manuel Gastéllum. Archivo: CAPUAO
El eje cultural Oaxaca Hierve el Agua se ha conformado a lo largo del siglo $\mathrm{xx}$, cuando los primeros exploradores y viajeros fueron eslabonado la experiencia del descubrir, conocer y reconocer esta ruta. Con una extensión cercana a los 70 kilómetros, se aglutinan poblaciones con patrimonio tangible e intangible, del que destacan zonas arqueológicas prehispánicas, arquitectura conventual y vernácula, paisaje natural, reservas ecológicas, así como tradiciones gastronómicas, artesanales, fiestas patronales, folclore, sistemas de gobierno comunitario, etcétera. Son reconocidos en esta ruta: Santa María el Tule, San Jerónimo Tlacochahuaya, Dainzú, Teotitlán del Valle, Lambityeco, Tlacolula, Santa Ana del Valle, Yagul, San Pablo Mitla, Hierve el Agua y Santiago Matatlán, entre los más importantes. Este eje patrimonial sigue consolidándose, para 2010 la UNESCO declaró a las

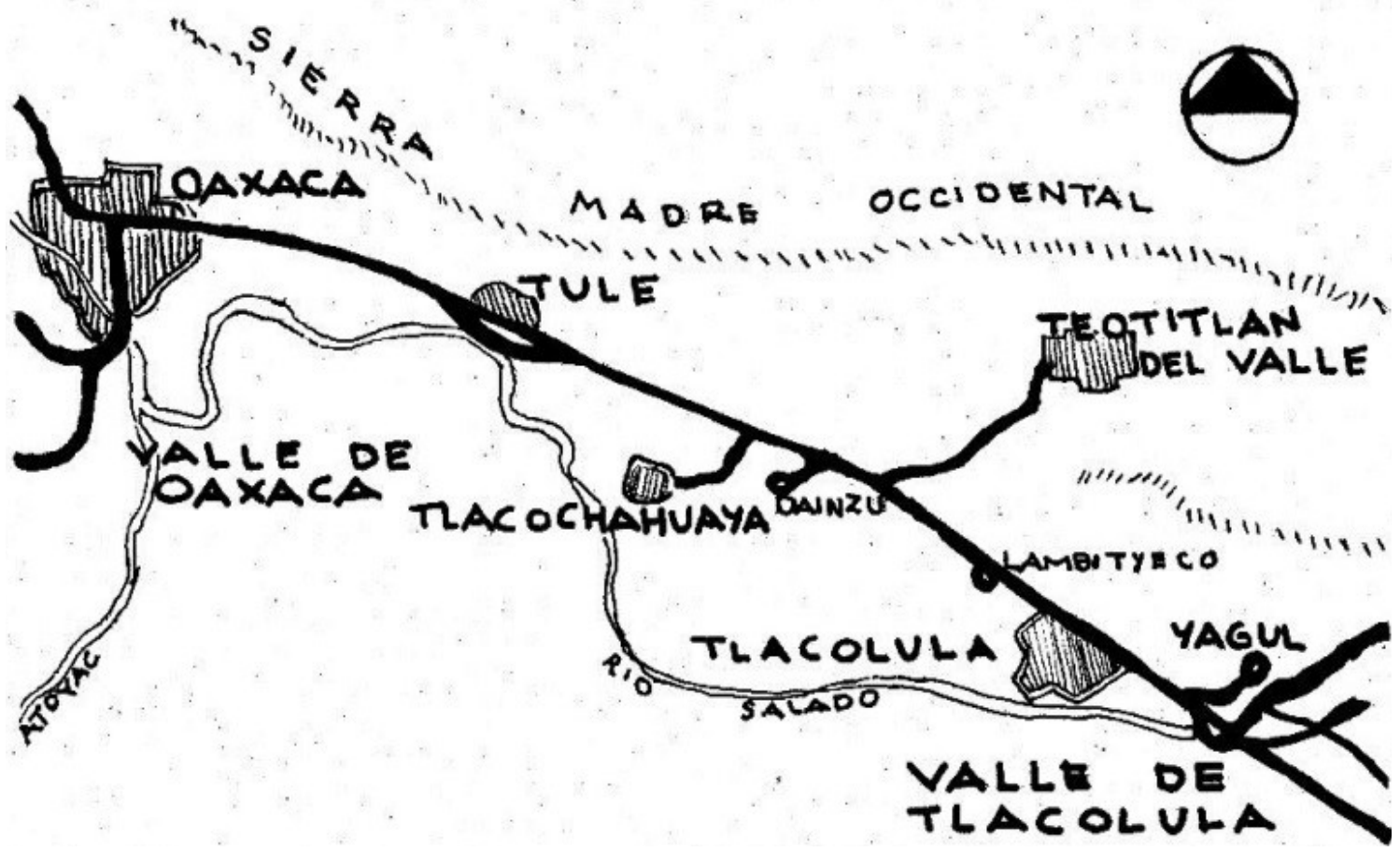


cuevas prehistóricas de Yagul como Patrimonio Cultural de la $\mathrm{Hu}-$ manidad, ya que en ellas:

se han encontrado restos arqueológicos y vestigios de arte rupestre que son testimonios de la vida de los primeros agricultores sedentarizados. En la cueva de Guilá Naquitz de han hallado semillas de 10,000 años de antigüedad, que constituyen los restos más tempranos de plantas domesticadas descubiertas hasta la fecha en el continente americano. ${ }^{1}$

Y también fragmentos de espigas de maíz, considerados los rastros más antiguos de su domesticación.

Teotitlán del Valle es una población de origen zapoteca del estado de Oaxaca que se ubica en el valle de Tlacolula, a 31 kilómetros hacia el oriente de la ciudad de Oaxaca. A este lugar se accede a través de la Carretera Federal 190, en dirección de la ciudad de Tlacolula. Llegando al kilómetro 27, se localiza una desviación hacia el norte con recorrido de 4 kilómetros que conduce hacia Teotitlán del Valle (imagen 1).

Teotitlán es un nombre de origen náhuatl con diversas interpretaciones que van desde las que expresan que el nombre significa «Lugar de dioses» (teotl, dios; tlán, lugar de), ${ }^{2}$ hasta aquella que indica que Teotitlán significa «entre las casas de dios». ${ }^{3}$ Coloquialmente los pobladores de Teotitlán se refieren a este lugar con el nombre zapoteco Xaaguia, que significa «debajo de la peña» o al pie del cerro, en referencia al cerro o picacho sagrado que se ubica junto al casco urbano al poniente del poblado.

Se desconoce la fecha exacta de la fundación de Teotitlán del Valle, sin embargo, algunos estudios recientes manifiestan la ocupación incipiente de este territorio desde la etapa de las aldeas, entre 4000 y 500 d.C., consolidando su población en el periodo subsecuente de los centros urbanos, entre el 500 y el 800 d.C., cuando existió allí un asentamiento regular. ${ }^{4}$ Durante la llegada de los españoles al valle de Oaxaca, diversos documentos religiosos describen la existencia de Teotitlán, al que mencionan como «Teutitlán», ${ }^{5}$ refiriéndose al mismo poblado como "Xaaguia», un sitio con 20 casas. $^{6}$

De acuerdo al análisis de otros documentos históricos, ${ }^{7}$ se afirma que entre 1582 y 1590 fue edificado el templo religioso, contribuyendo a consolidar la población a finales del siglo XVI y durante todo el

1 UnEsco, «Cuevas prehistóricas de Yagul y Mitla en los Valles Centrales de Oaxaca».

2 Martínez Gracida, «Colección de cuadros sinópticos de los pueblos, haciendas y ranchos del estado libre y soberano de Oaxaca».

3 Salazar, Boletines de la Biblioteca Pública del Estado; Bradomín, Toponimia de Oaxaca (Crítica etimológica).

4 Rodrigo Álvarez, Historia general del estado de Oaxaca.

5 Covarrubias Salazar, y Zárate Martínez, Teotitlán del Valle. Un pueblo del Valle de Tlacolula, Oaxaca.

6 Covarrubias Salazar, y Zárate Martínez, Teotitlán del Valle..., cita a Dávila, 1955.

7 Covarrubias Salazar, y Zárate Martínez, Teotitlán del Valle... 
siglo XVII. ${ }^{8}$ Para este último periodo, el actual estado de Oaxaca se dividió en 18 partidos gobernados por subdelegados, siendo Teotitlán del Valle el primero de ellos, lo cual pudo ser influyente para que Teotitlán se volviera muy importante en el tejido de cobijas y sarapes de lana, cuchillos, machetes, básculas, telas, pescado y sal. ${ }^{9}$ Gerhard ${ }^{10}$ indica que para el año 1742, en Teotitlán, con rango de alcaldía mayor, se cultivaba algodón, azúcar, frijol, grana cochinilla, maíz y trigo, aspecto importante para su desarrollo, por hallarse inserto dentro de la red comercial de los Valles Centrales. Para la tercera década del siglo xIx Mühlenpford $t^{11}$ describe a Teutitlán como un pueblo grande y bonito habitado por 400 familias, con bella iglesia, vistosos edificios públicos y casas particulares, la mayoría construidas con ladrillo, con aspecto de ser espaciosas y confortables.

Es una de las primeras poblaciones de los valles de Oaxaca, y como tal, es un reducto cultural en el cual se amalgaman diversas manifestaciones, como el tejido de sarapes de lana y algodón con procesos naturales de teñido, entre los que destaca la grana cochinilla. Esta industria cultural se desarrolla intensamente desde el núcleo familiar, siendo una actividad económica intergeneracional. A lo largo de la segunda mitad del siglo xx se internacionaliza con la exportación y las constantes participaciones de artesanos en exposiciones en países europeos. Sus temas estéticos tradicionales conviven con reproducciones de Pablo Picasso, Joan Miró, Salvador Dalí, Rufino Tamayo, Diego Rivera y Francisco Toledo. Recientemente los jóvenes tejedores están desarrollando estrategias contemporáneas textiles al cursar talleres experimentales con la dirección de artistas provenientes de distintos estados del país. Entre los artesanos renombrados del siglo xx y xxi destacan Juan y Manuel Bazán, Eligio Bazán Martínez, José Hernández, Isacc Vásquez García, Felipe Hernández, Demetrio Bautista, Fortino Olivera, Emilio Mendoza y Arnulfo Mendoza Ruiz.

Los textiles de Teotitlán del Valle son una expresión cultural que forma parte de un conjunto más amplio, por ejemplo, la elaboración de velas de cera escamada para las fiestas patronales, bodas y mayordomías cuenta con amplio reconocimiento por su manufactura y combinación de colores; al igual que la Danza de la Pluma ${ }^{12}$ como representación dancística sobre la conquista de Tenochtitlán, la cual, para José María Bradomín, refleja el «aire fúnebre, lúgubre y triste [...] es una marcha a la tumba [...] ritual [...] trágico destino de la raza». ${ }^{13}$ Así es la pervivencia de tradiciones y costumbres, otras se han transformado e inclusive perdido, como el sistema de orden moral impuesto por la autoridad municipal, que bajo el nombre de $\mathrm{Gu}$ -

8 Carmagnani, El regreso de los dioses. El proceso de reconstrucción de la identidad étnica en Oaxaca, Siglos XVII y XVIII.

9 Covarrubias, y Zárate Martínez, Teotitlán del Valle...

10 Gerhard, México en 1742.

11 Mühlenpfordt, Ensayo de una descripción fiel de la República de México. Con especial referencia a su geografía, etnografía y estadística. El estado de Oaxaca.

12 Esta Danza también se practica en poblaciones de los Valles Centrales como Santa Ana del Valle, Cuilapam, Zaachila, Zimatlán y San Martín Tilcajete, entre otros.

13 Bradomín, Oaxaca en la tradición, 181. 
lavas se dedicaba a vigilar el comportamiento social entre hombres y mujeres con atribuciones para aplicar los correctivos necesarios a quienes faltaran a la moral social. Es importante destacar la tradición de servicio a la comunidad por parte de los hombres, quienes iniciaban su labor al ser informantes de los Gulavas para después iniciar la trayectoria en la administración municipal, desde topil, presidente municipal y parte del consejo de ancianos. Pero, sin duda, una de sus principales características culturales es la permanencia del uso de la lengua zapoteca, ${ }^{14}$ ya que en la vida cotidiana de Teotitlán es común escucharla en la comunicación entre los pobladores de distintas edades, y esto es posible por la transmisión oral del zapoteco en la familia, y también porque en el nivel preescolar — como en el caso del centro Josefa Ortiz de Domínguez- la educación es bilingüe: español-zapoteco, con lo cual se garantiza la permanencia de la lengua en la población.

Aunado a estas expresiones patrimoniales, existe en la población la percepción sobre la relación orográfica de la traza urbana, y deviene desde su fundación prehispánica. En los documentos escritos por el fraile dominico Francisco de Burgoa, dice a este respecto:

fue la fundación de este pueblo antiquísima, de las primeras de la Zapoteca, y sus señores, por el sitio de este ídolo, muy temidos, fingiendo su origen haber venido del Cielo, en figura de ave, en una luminosa constelación, con que llamaban a su habitación, y todo se ordenaba ha mayor culto, para ver con horrores espantosos, y respetado; el paraje donde se avecindaron fue entre peñas, seco, y de muy saludable temple, y aún abrigado del Norte [...] halló satanás la altura de su apetito, y lo remontado de su altiva condición, escogió la cima del Peñasco. ${ }^{15}$

Sin duda, esta presencia orográfica desde la fundación de Teotitlán del Valle está impregnada de rituales antiguos prehispánicos y de una carga cultural que pervive adaptándose a nuevas tradiciones religiosas, es de esta manera que el cerro Picacho, «Quia-less» o «Gia Bets» para los pobladores, es un referente simbólico de su origen basado en su orientación arqueo-astronómica, por lo que su condición orográfica circundante está nombrada como Cerro Grande «Dan Roo», Cerro de la Piedras Gemelas «Dain Yebetz», Cerro de Yagalán «Dain Yaglan» y el Cerro de la Piedra Delgada «Dain Yeles».

14 El zapoteco es una lengua que se habla en la mitad del territorio oaxaqueño, y se clasifica en cuatro grupos: del Valle, del Istmo, de la Sierra Norte y Sierra Sur, ocupando el tercer lugar a nivel nacional entre las lenguas de mayor importancia en México.

15 Burgoa, Geográfica descripción, de la septentrional, del Polo Ártico de la América, folio 267 . 


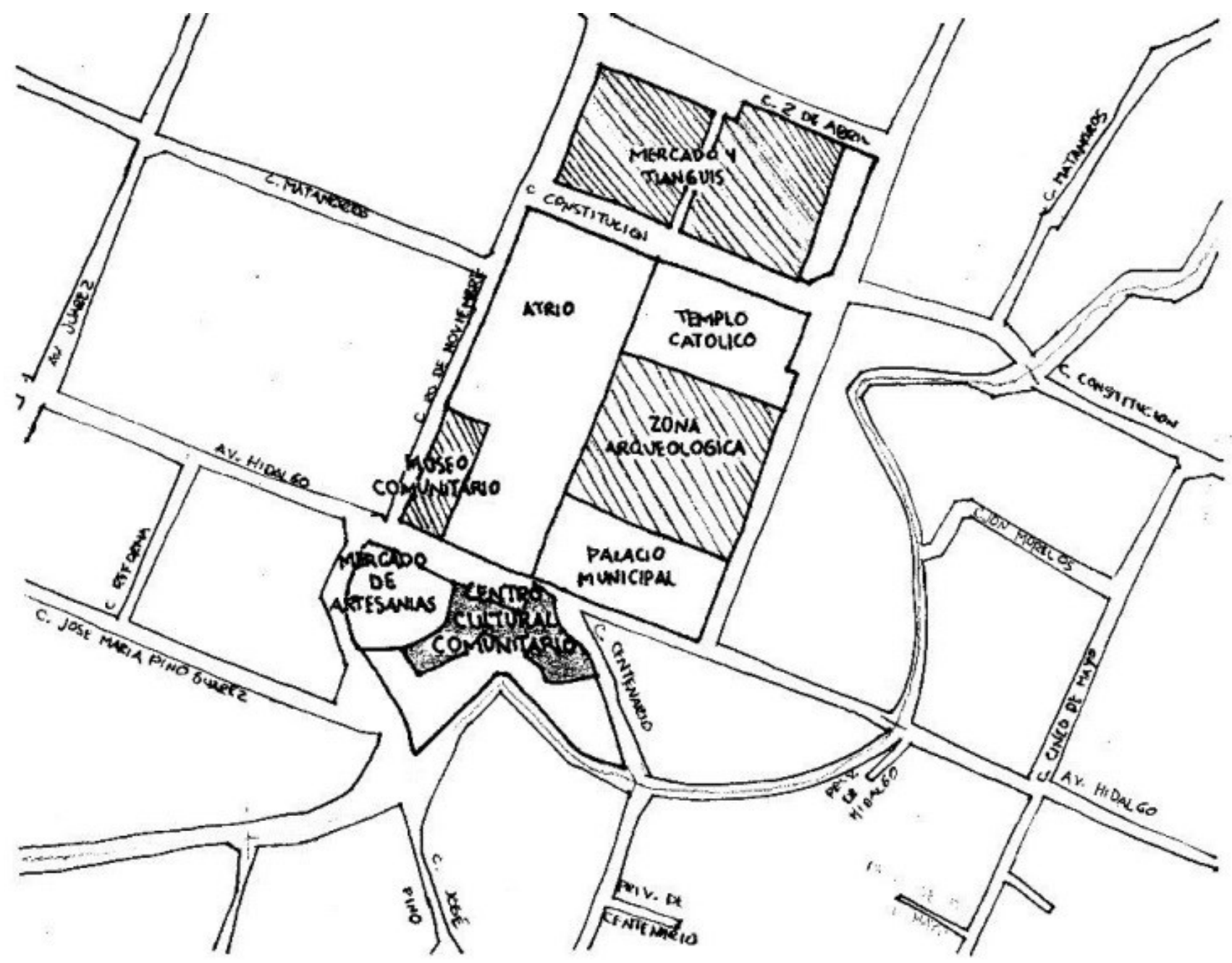

Centro físico de Teotition del Valle en el entorno del conjunto religioso

Imagen 2. Esquema del centro urbano Teotitlán del Valle. Autor: Juan Manuel Gastéllum. Archivo: CAPUAO. 


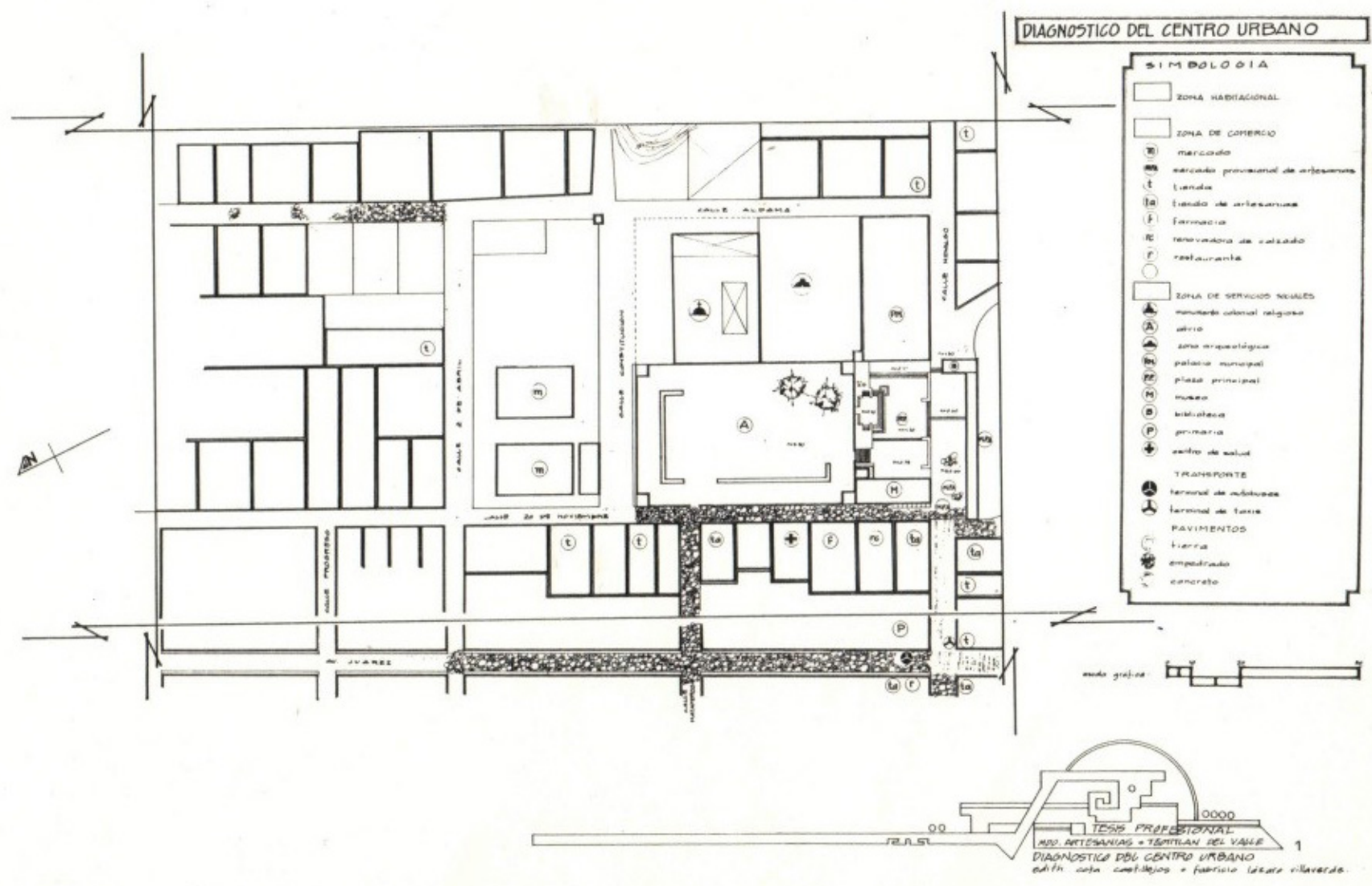

Imagen 3. Esquema de equipamiento urbano, centro de Teotitlán del VaIle. Autores: Edith Cota Castillejos y Fabricio Lázaro Archivo: CAPUAO. 


\section{Urbanismo político-religioso y su devenir cultural}

Teotitlán del Valle cuenta con una traza de origen prehispánico donde se desplantaban los templos y viviendas, ejemplo de ello son las preexistencias de este origen en la fachada del templo del siglo XVI, en el interior de la casa del cura, en la capilla posas, donde fueron incrustadas piedras labradas de distintos tamaños y bajo relieves de la época prehispánica. El vestigio más importante se localiza al sur del templo, donde fue descubierto un basamento con evidente manufactura prehispánica en el uso de la piedra y presencia del tablero con la característica greca posteriormente desarrollada en Mitla. La permanencia del uso abierto del espacio está enfatizada en las dimensiones del atrio, así como en la práctica del tianguis al norte del templo. La notoria diferencia de altura entre el atrio y la plaza municipal es evidencia de las plataformas con las cuales se estructuraba la ciudad prehispánica.

Sin embargo, la traza y el equipamiento urbano después del siglo xvi en Teotitlán del Valle integraron el conjunto religioso-político y comercial, con el cual la población se desarrollaría hasta la actualidad. De esta manera, el urbanismo novohispánico se hace tangible en

Imagen 4. Corredor artesanal frente al Museo Comunitario. Autor: Edith Cota Castillejos. Archivo: CAPUAO. el ordenamiento espacial manifiesto en la relación entre el templo del siglo XVI, el palacio municipal y el área del mercado o tianguis (ver imagen 2). Los tres elementos urbanos tienen características propias

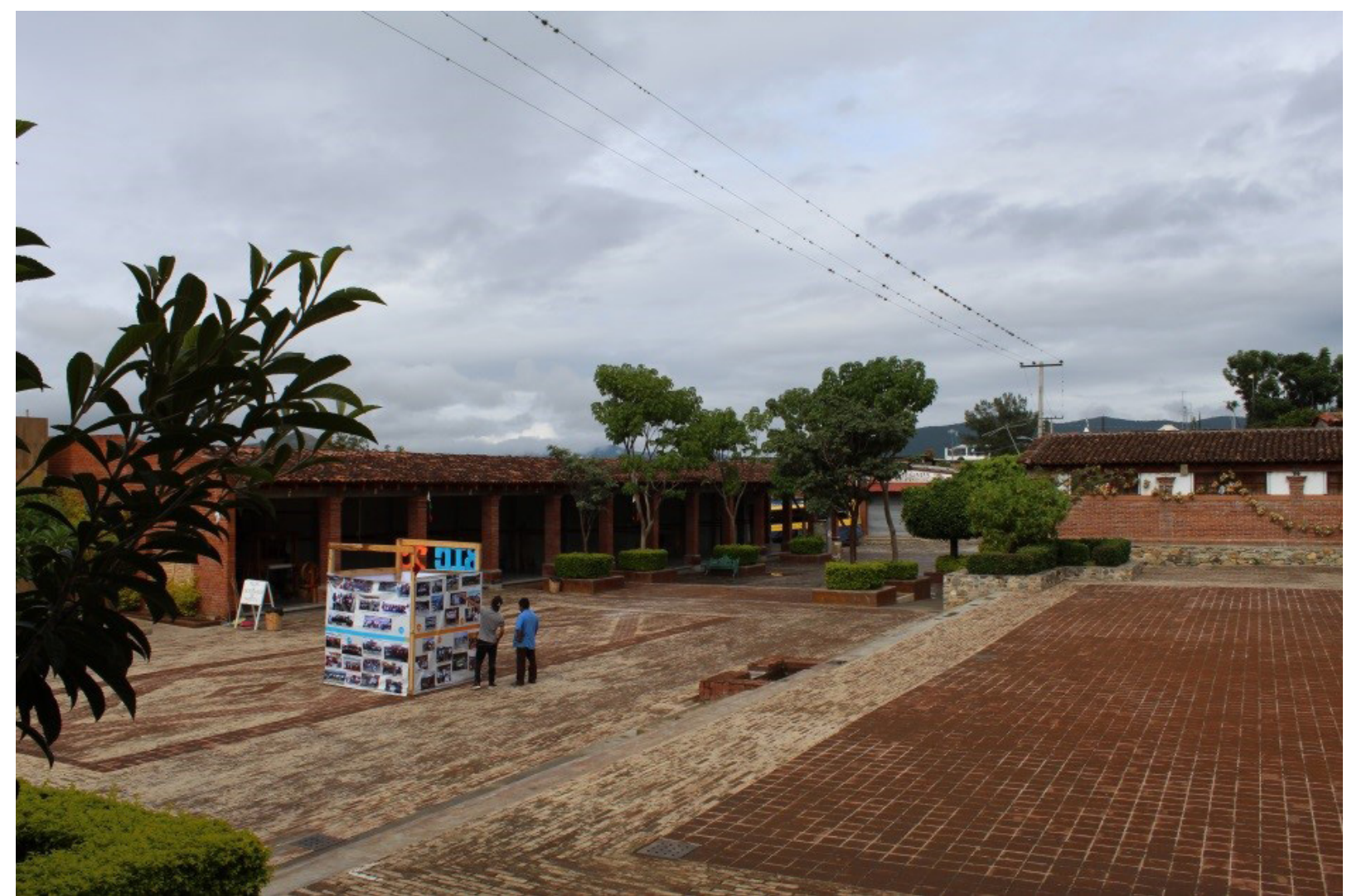




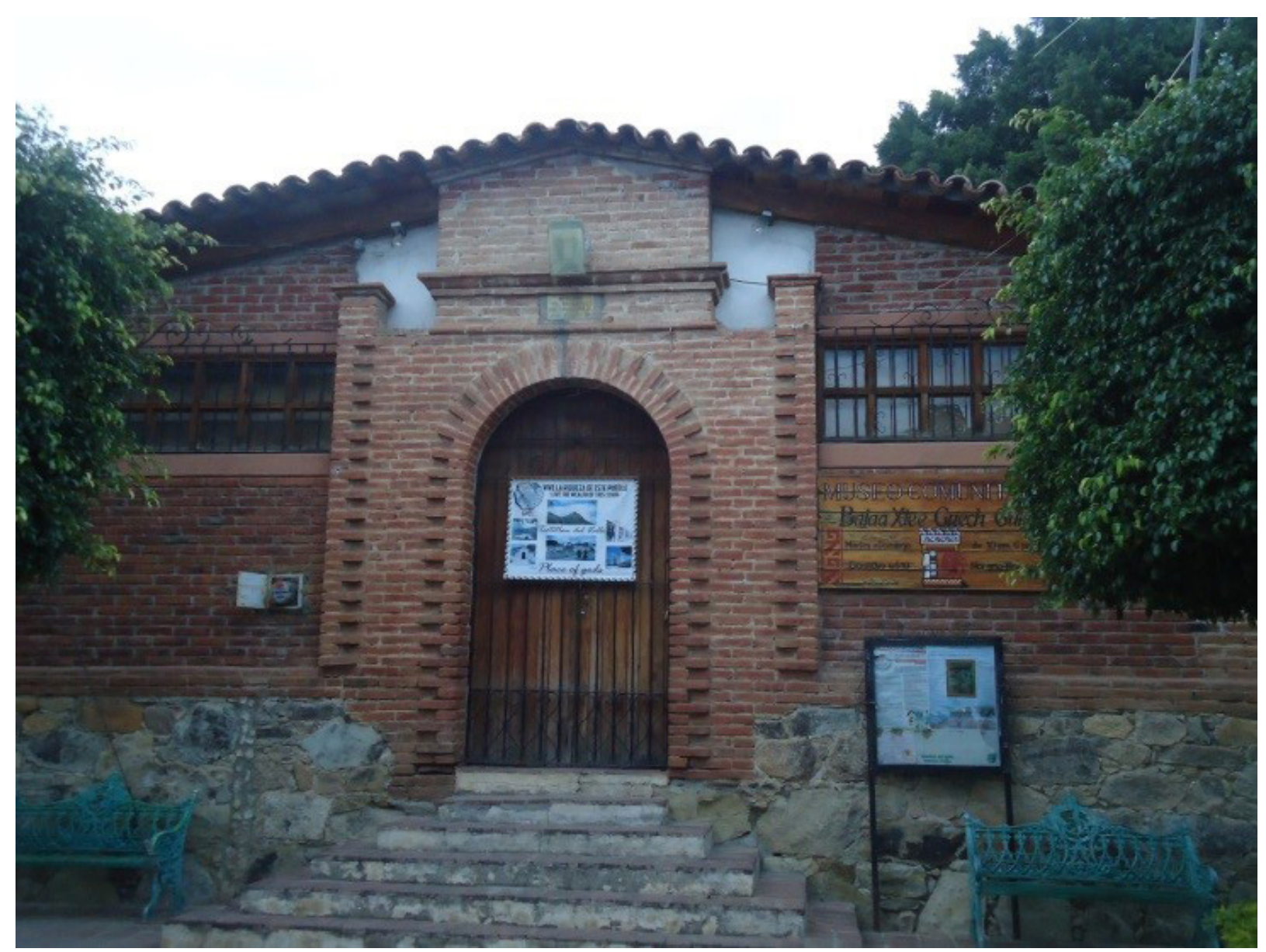

Imagen 5. Fachada de ingreso al Museo Comunitario, antes Mercado Municipal. Autor: Fabricio Lázaro. Archivo: CAPUAO. que les otorgan una singularidad a través de la cual se hace notoria su armonía e integración (ver imagen 3).

Estos espacios urbanos son de uso frecuente, a pesar de que en el caso de la plaza municipal y el mercado han tenido distintas modificaciones para mejorar su funcionamiento. Por ejemplo, la plaza municipal es el lugar de actividades políticas como la asamblea del pueblo, fiestas anuales administrativas, actividades culturales y educativas, etcétera. El área dedicada al comercio de abasto ha tenido distintas soluciones, entre las que destaca la construcción del mercado El Progreso en 1940 como un espacio rectangular de manufactura en ladrillo y cubierta de madera y teja con dos pendientes, ubicado al poniente del palacio municipal. Tiempo después el mercado fue reubicado al norte del templo, a través de galeras y espacios abiertos para el tianguis, donde actualmente funciona, con otras construcciones, para tal fin, así como también una cancha de basquetbol. El comercio artesanal funciona en los domicilios particulares, sin embargo, en 1973 se construyó al sur del palacio municipal un corredor longitudinal de oriente a poniente a base de ladrillo aparente en muros y columnas, viguería de madera y teja, donde un grupo de artesanos exhibe y comercializa — desde entonces- los tapetes característicos de Teotitlán del Valle (ver imagen 4). En la actualidad, el centro urbano no cuenta con un área de esparcimiento definido como parque o jardín municipal.

Los espacios dedicados a la conservación del patrimonio y a la difusión de la cultura se desarrollan específicamente en dos lugares. El 


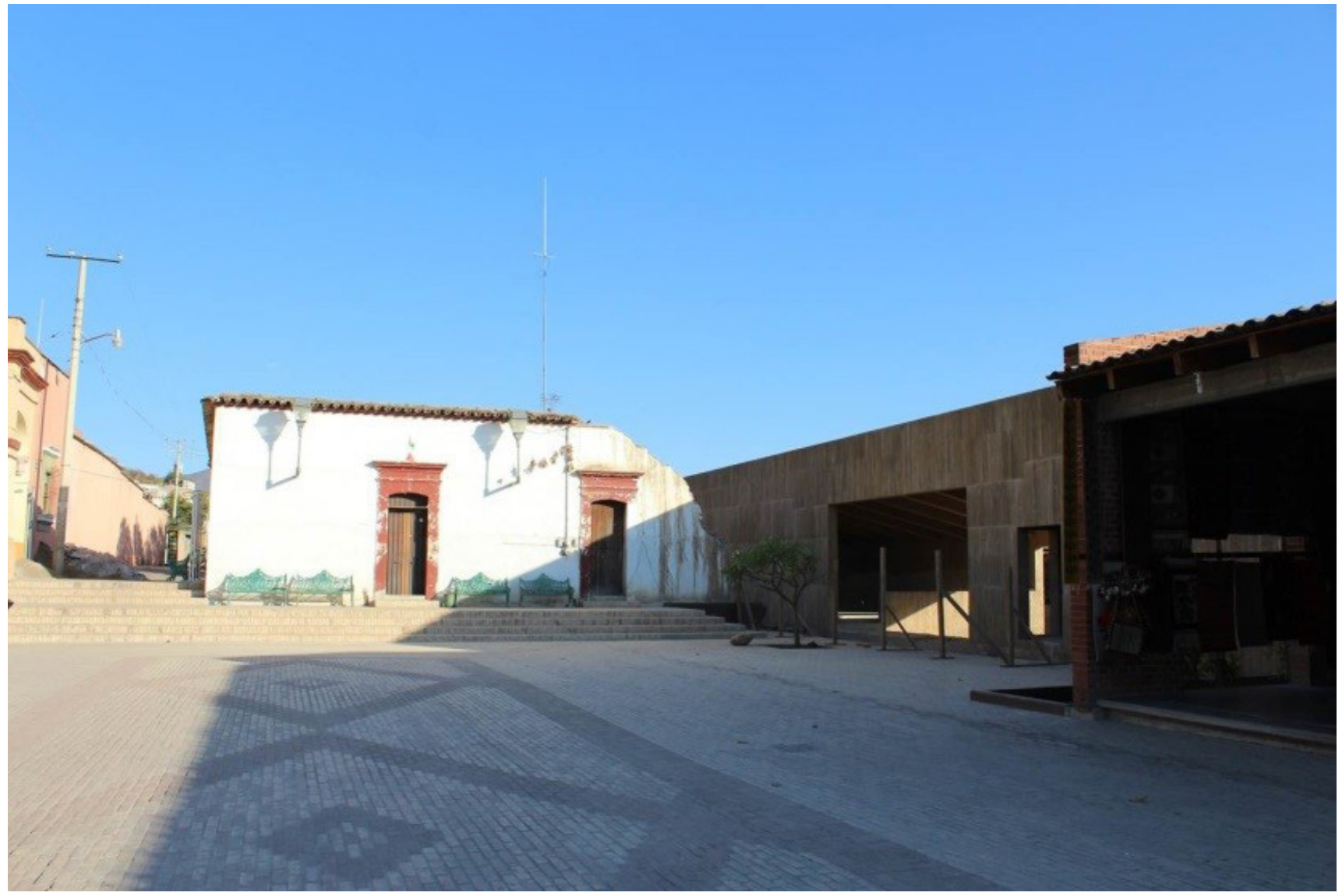

Imagen 6. Biblioteca Municipal Pablo Picasso. Autor: Edith Cota Castillejos. Archivo: CAPUAO. 

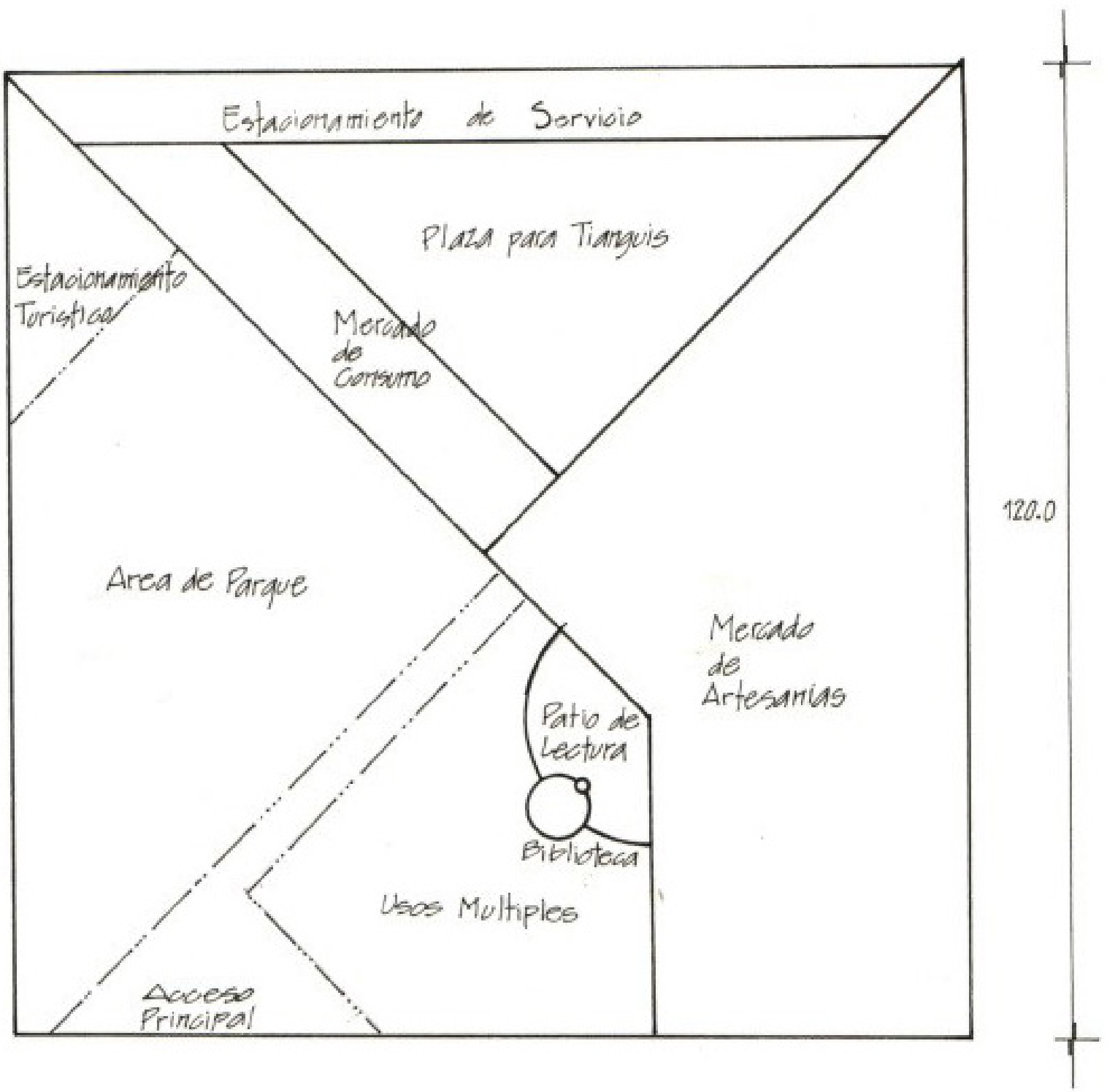

Imagen 7. Esquema de zonificación, propuesta de tesis. Autores: Edith Cota Castillejos y Fabricio Lázaro. Archivo: CAPUAO. 
primero es la construcción que funcionó como mercado, que se reutilizó desde 1994 como el Museo Comunitario (ver imagen 5), ejemplo de la iniciativa federal para proteger y exhibir la idiosincrasia cultural de las comunidades en aras de que sean los habitantes de las poblaciones quienes decidan las formas adecuadas para fortalecer su cultura con este equipamiento.

El museo que lleva el nombre Balaa Xte Genchi Gulal —Sombra o Casa del pueblo antiguo - es para los habitantes de Teotitlán del Valle el refugio donde se manifiesta su cultura para conocimiento de visitantes. Este museo, si bien no cuenta con una museografía adecuada a su función, es importante mencionar que es un lugar que recupera un edificio modesto y bien construido hace cerca de 80 años. Por otro lado, la Biblioteca Municipal Pablo Picasso se ubica en una construcción de forma rectangular, cubierta de teja con una pendiente, en la que predomina el macizo sobre el vano, con dos puertas de acceso y cuyo volumen define la plaza municipal al estar en la esquina suroriente entre el corredor artesanal y el palacio municipal (ver imagen 6).

De esta manera, la plaza municipal se conforma por estos edificios: museo comunitario, corredor artesanal, biblioteca, acceso al atrio parroquial y el palacio municipal de un solo nivel, resuelto en una sola crujía con corredor al frente y arcos de medio punto con remate al centro. En años recientes la plaza ha sido modificada en el tratamiento de pisos, incorporación de jardineras y dos fuentes de agua.

Desde $1995,{ }^{16}$ los autores de esta investigación, al realizar la tesis de licenciatura en Arquitectura con el título Mercado de Artesanías. Teotitlán del Valle, Oaxaca (investigación del sitio sobre las condiciones urbanas que tenía el centro), determinó la necesidad de estructurar este conjunto para mejorar sus condiciones funcionales. De este análisis, la propuesta fue definir tres zonas funcionales politico-administrativas integradas por el palacio municipal, recuperar para nuevas funciones administrativas el corredor artesanal y consolidar esta zona con el Museo Comunitario en el edificio actual (ver imagen 7 ).

La zona religiosa se convertiría en el núcleo articulador para definir la zona comercial - ubicada al norte - con un nuevo mercado de abastos, área de tianguis, mercado de artesanías, jardín municipal, biblioteca, plaza de usos múltiples y estacionamientos. Sin embargo, el impacto de esta tesis en el mejoramiento del núcleo histórico fue nulo, ya que al ser un trabajo académico estudiantil quedó limitado en su integración como elemento del proyecto político municipal y, por consiguiente, en su gestión para desarrollarse a nivel de proyecto ejecutivo. Como resultado académico, la tesis brindó la observación y registro de las condiciones patrimoniales del centro de Teotitlán del Valle, y constató con el paso de los años la permanecia de usos, fisonomía e identidad de este conjunto.

16 Lázaro, y Cota, Mercado de Artesanías. Teotitlán del valle, Oaxaca. 


\section{Un Centro Cultural Comunitario para Teotitlán del Valle}

En 2013 el Gobierno del Estado de Oaxaca crea el Centro de Diseño de Oaxaca (CDO) como un organismo descentralizado para fomentar la cultura del diseño en las actividades culturales y económicas estatales, con la organización de talleres, conferencias, publicaciones, prototipos, inserción en proyectos artesanales, etcétera. En este entorno institucional y de colaboradores en el diseño contemporáneo, CDO invita al despacho de arquitectura productora integrado por Abel Perles (Argentina), Carlos Bedoya (México), Víctor Jaime (México) y Wonne Ickx (Bélgica) para desarrollar el Centro Cultural Comunitario (CCC) de Teotitlán del Valle.

El anteproyecto y proyecto arquitectónico se desarrolla entre 2015 y 2016, a decir de los autores, con base en la investigación en el lugar para determinar con las autoridades municipales y población en general las funciones necesarias. El programa arquitectónico se integra por recepción, tienda, salas de exposiciones, museo arqueológico, talleres, sanitarios, biblioteca y área de servicios; importante fue la elección del lugar para su desarrollo y posterior construcción. El reto es complejo porque busca integrar la separación de espacios que ya existen en el centro de la traza, como la biblioteca y el Museo Comunitario, y agregar nuevos espacios. La estrategia urbano-arquitectónica del anteproyecto apuesta por concentrar en tres volúmenes el programa arquitectónico, resolviendo utilizar un predio municipal en situación residual, ubicado en el lado sur del corredor artesanal y biblioteca municipal. El terreno cuenta con una poligonal irregular y abrupta pendiente que termina en el cauce de un arroyo que atraviesa la población (ver imagen 8).

El anteproyecto solo es conocido por los actores involucrados, sin embargo, existen imágenes donde se observa la estrategia proyectual

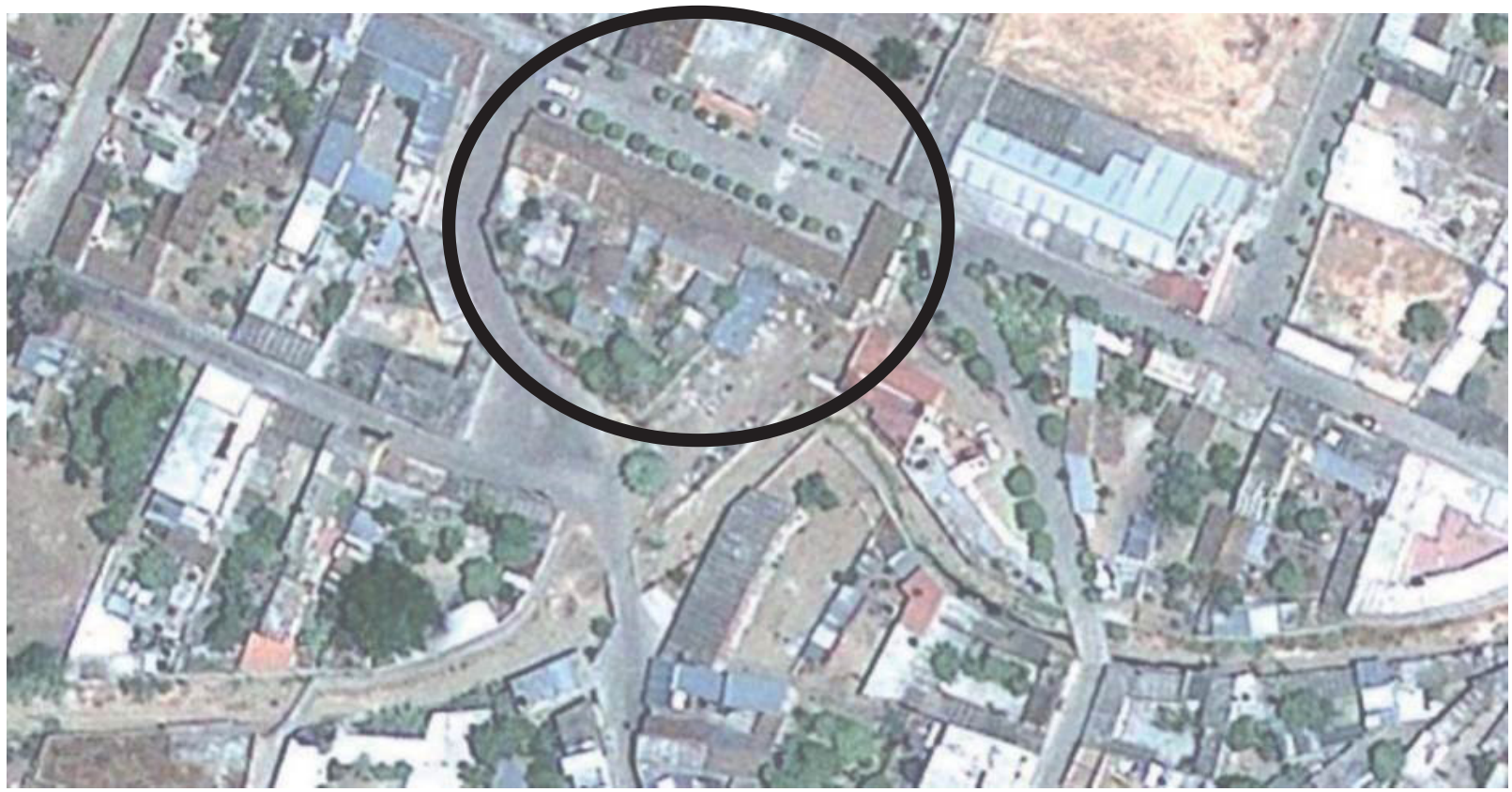




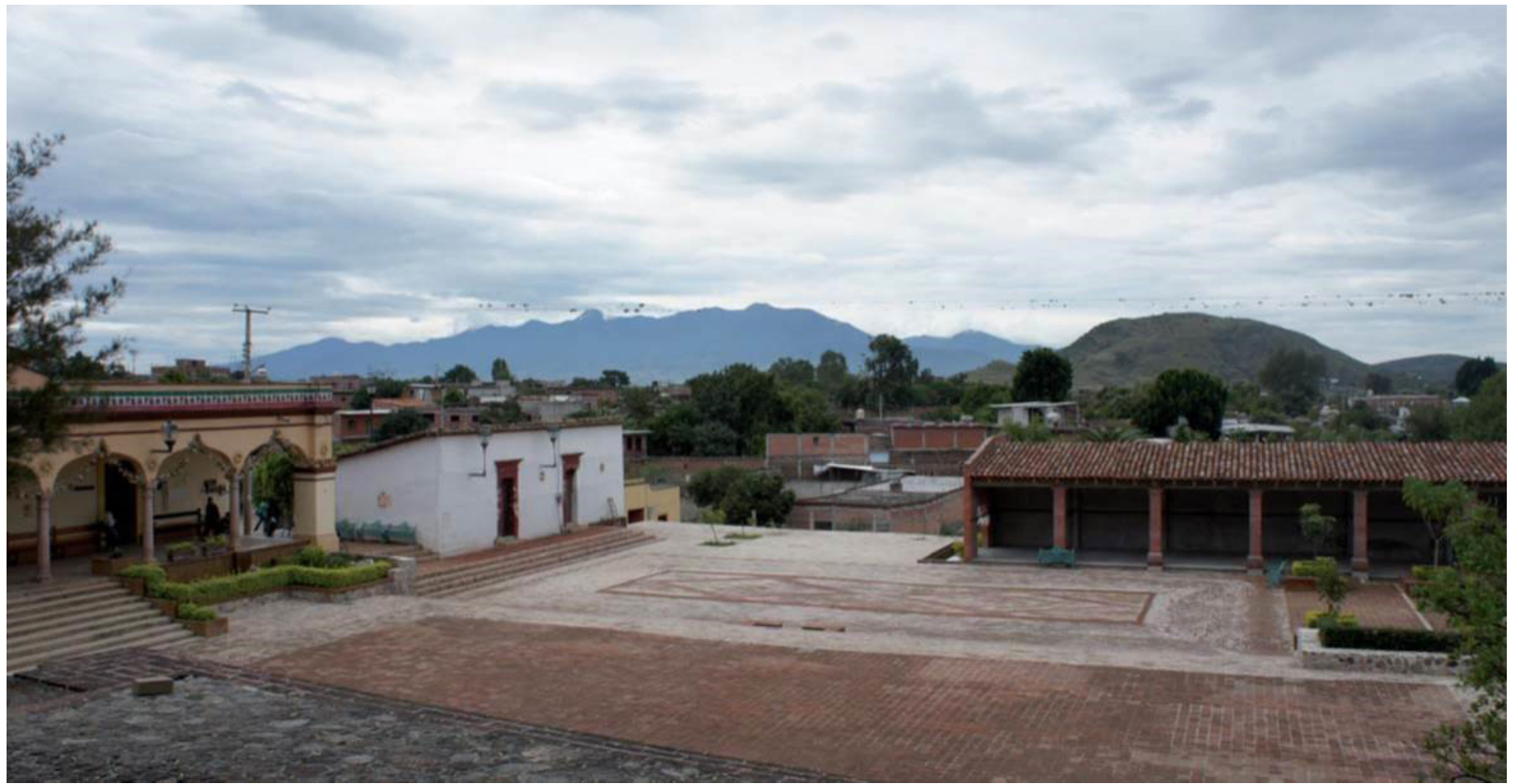

Imagen 9. Liberación de acceso al terreno para el Centro

Cultural Comunitario. Autor: Taller Productora.

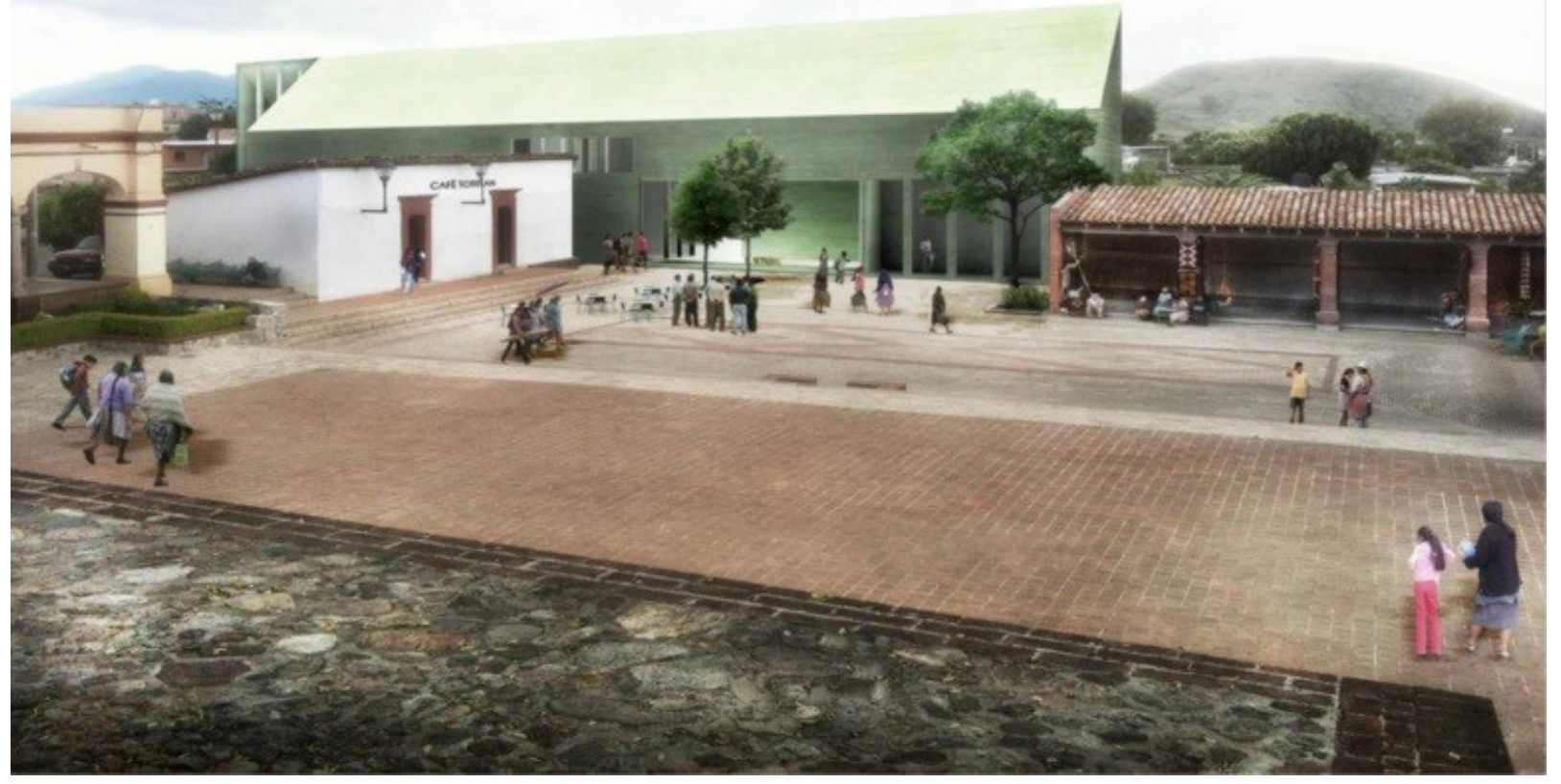

Imagen 10. Primer propuesta volumétrica para el Centro Cultural Comunitario. Autor: Taller Productora.. 


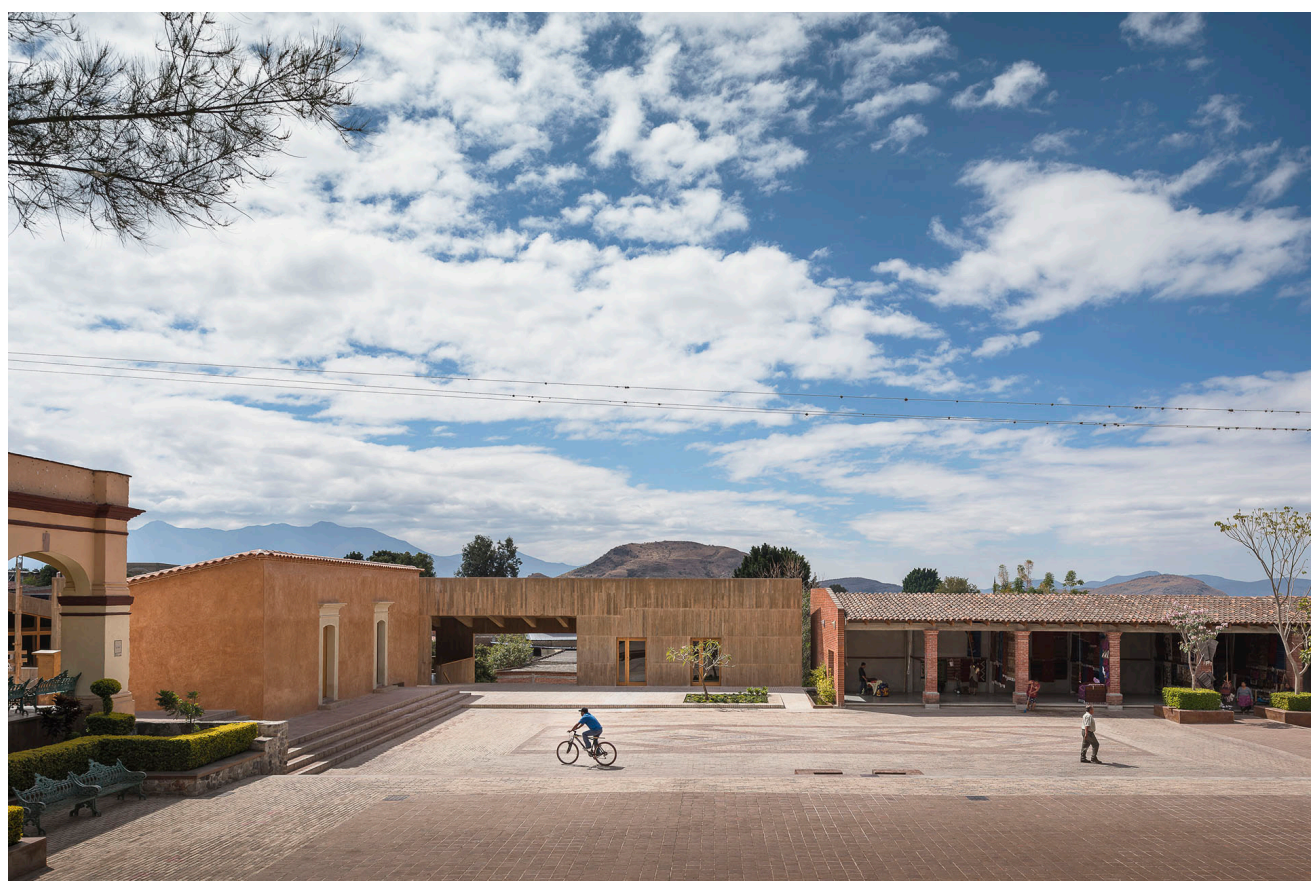

Imagen 11. Imagen del Centro

Cultural Comunitario (CCC) construido. Autor: Taller Productora.

Imagen 12. Vista sureste del Centro Cultural Comunitario. Autor: Fabricio Lázaro. Archivo: CAPUAO. de Productora, que consiste en desplantar un volúmen rectangular desde el nivel más bajo del terreno, en una trayectoria oriente poniente que se retrae del alineamiento del corredor artesanal. Este desplazamiento es determinado por el volúmen de la biblioteca, el cual está en eje con el corredor, integrándose en esquina. Sin embargo, para ubicar el acceso al Centro Cultural en esta intersección fue necesario demoler una parte del corredor artesanal para generar una microplaza de acceso (ver imagen 9).

El volúmen del CCC es de una escala monumental, no solo por el desplante desde el nivel más bajo del terreno, sino que también a nivel de la plaza municipal resulta en una altura fuera de escala del contexto en el que predominan casas de un solo nivel, con cubiertas a una o dos pendientes con teja. Con la presencia en el conjunto de es-

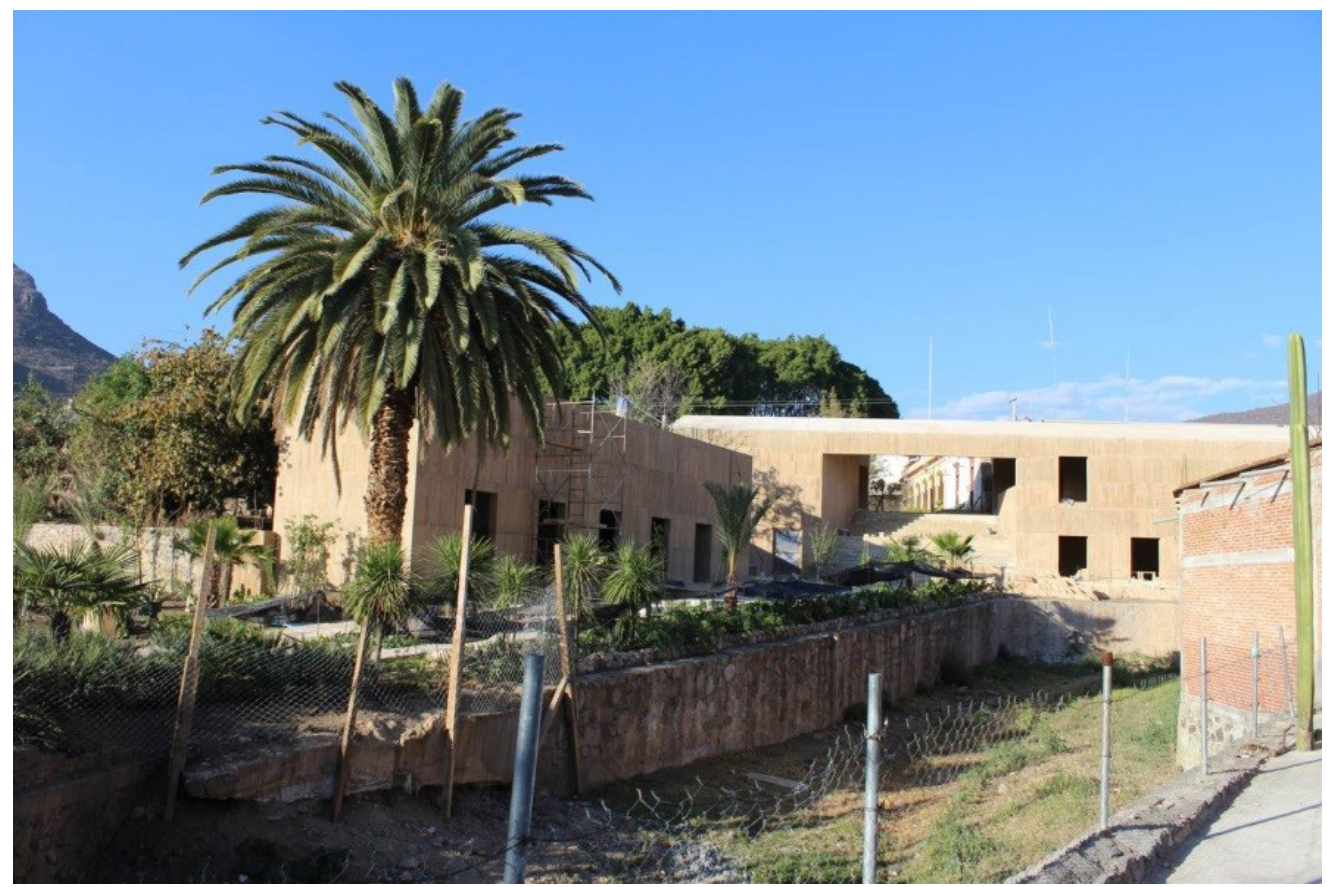


te volúmen, la visual hacia los cerros circundantes y definitorios de la identidad rural, son negados absolutamente por el excesivo protagonismo formal en esta primera versión del proyecto (ver imagen 10).

Una escalera monumental en recuerdo de aquellas plataformas prehispánicas funge como mirador enmarcado y también como un auditorio al aire libre para distintas actividades. Aunado a esta desmesura, el acabado propuesto de concreto pigmentado con una tonalidad verde - a semejaza del color de la cantera de la ciudad de Oaxaca- es disonante en el contexto de Teotitlán del Valle, caracterizado por la materialidad de la tierra en adobes, tejas, madera y el inconfundible ladrillo aparente usado en distintos aparejos, realizados por los constructores locales. Sin embargo, esta materialidad tradicional fue soslayada por el taller Productora, a pesar de argumentar que «formalmente el proyecto se rige por la estética del entorno, que determina los parámetros de altura, y materialidad $»,{ }^{17}$ justificando la tectónica del concreto como la única posibilidad para resolver técnicamente la escala del proyecto, es decir, una circunstancia del terreno con serios inconvenientes topográficos fue convertida en el punto de partida para la elección del material y su expresividad en el contexto, «el Centro Cultural utiliza una paleta mínima de materiales de elaboración local (concreto pigmentado, madera, baldosas de barro y ladrillo) para integrarse con el entorno». ${ }^{18}$ Esto es un contraste justificado desde la técnica constructiva a expensas de una lectura contextual desde la tradición constructiva (ver imagen 11).

Finalmente, el proyecto tuvo modificaciones necesarias que van desde las presupuestales - financiadas exclusivamente por recursos federales - hasta las funcionales, con las cuales, la escala de la intervención se redujo, consiguiendo estabilizar el predominio de la horizontalidad del conjunto arquitectónico. El color verdoso dio paso a la pigmentación del concreto en ocre, tratando de emular la coloración de la tierra y los adobes, pero contradiciendo la horizontalidad por la verticalidad de la cimbra aparente utilizada para el acabado final del concreto. Durante la construcción fue técnicamente necesario tapiar un pozo de agua potable que dotara a los vecinos del lugar y así resolviera un posible problema de humedad en el edificio. La existencia de otro pozo en la parte más baja del terreno fue utilizado por el ccc para el servicio de los núcleos sanitarios (ver imagen 12).

El cuerpo principal del cCC sigue la traza del corredor artesanal, y cambia suavemente por la dirección de la calle, que asciende a la plaza municipal, y por el trazo del arroyo con el que colinda. Se desarrolla una terraza en este cuerpo del edificio para observar la orografía circundante. El Museo Comunitario se proyectó en el nivel por debajo de la cota más baja del terreno con una sala continua, integrando en el lado oriente una espectacular triple altura con una escalera suspendida, pero este vacío refleja la escala de la excavación en el terreno para desplantar técnicamente el edificio (ver imagen 13).

La construcción del ccc fue por etapas, quedando suspendidas por un tiempo, dado que los recursos económicos no dependían de 


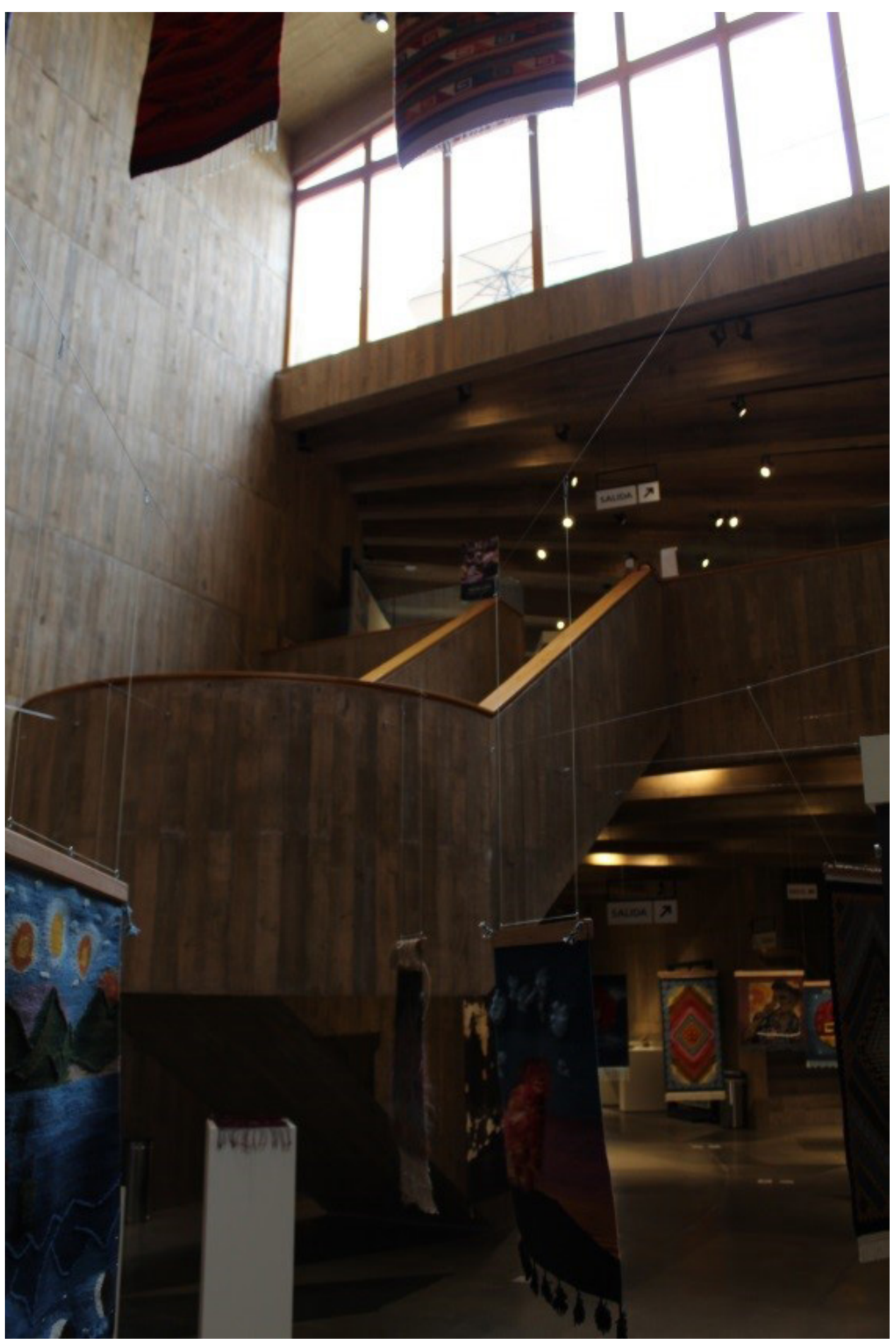

Imagen 13. Sala de triple altura, Centro Cultural

Comunitario. Autor: Edith Cota Castillejos. Archivo: CAPUAO 


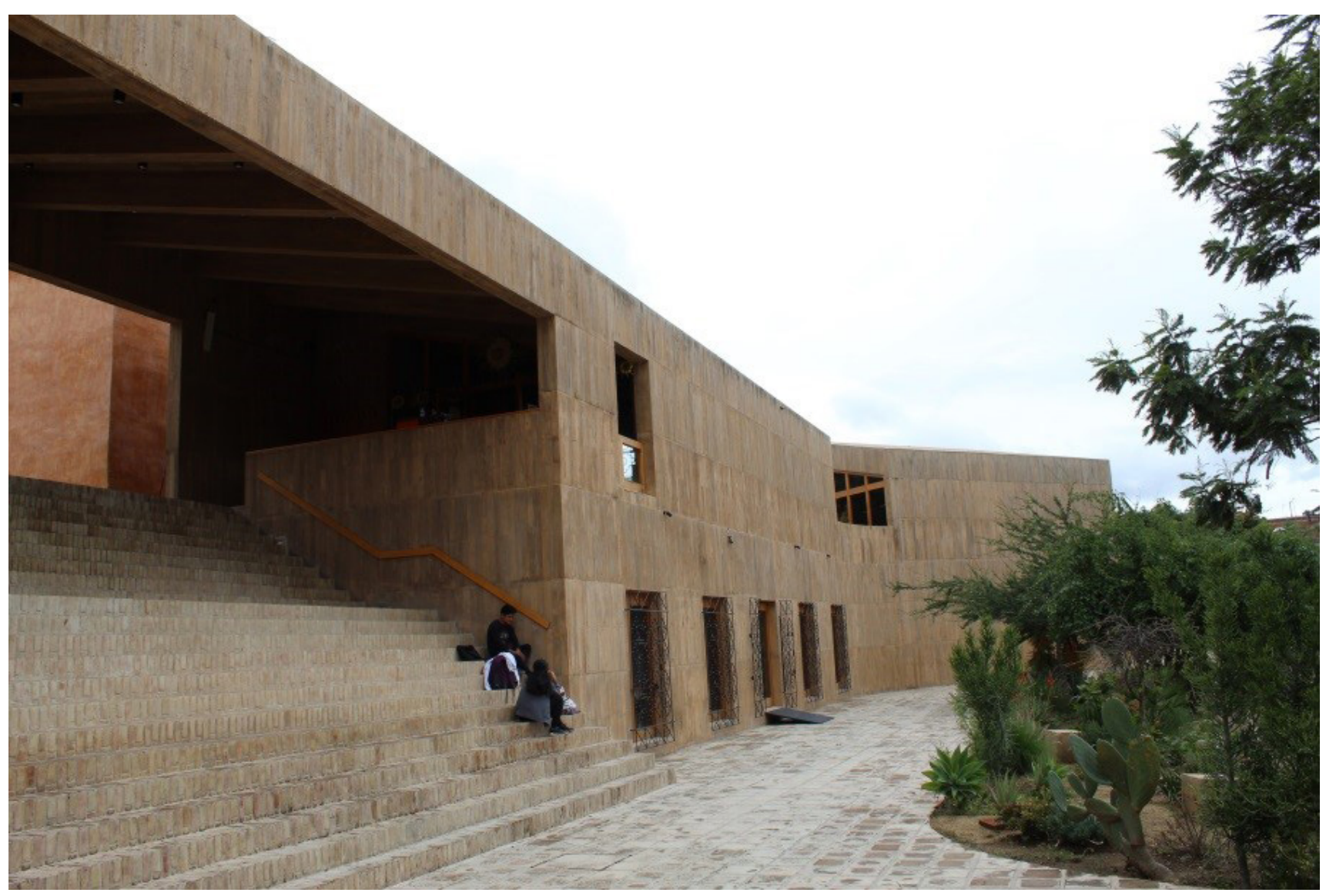

Imagen 14.Escalera articuladora de niveles en el Centro Cultural Comunitario. Autor: Fabricio Lázaro. Archivo: CAPUAO. 
la autoridad municipal ni estatal. Lograda su terminación en obra negra, quedó el edificio vacío a falta de mobiliario para las funciones, así como de todo el sistema de instalaciones, desde las elementales hasta las especiales. Después de la incertidumbre generada en este proceso, finalmente fue inaugurado el cCC, en agosto de 2018, sin lograr resolver problemas fundamentales como la inoperancia del espacio destinado al Museo Comunitario para exhibir piezas arqueológicas de barro, dada la excesiva humedad en el interior, debido principalmente a la existencia del cuerpo de agua tapiado a la cercanía con el arroyo, a pesar de estar delimitado por muros de contención, al igual que la transferencia de humedad que el concreto tiene de no ser tratado para evitar esta condición patológica.

La escalera monumental que une la plaza municipal con el andador, metros abajo, es la única opción para subir o bajar, sus peldaños son continuos, sin descanso y con una huella mínima, convirtiéndose en un serio peligro para todas las personas, sobre todo para las de edad avanzada, quienes solo tienen a su disposición un pasamanos imposible de asir (ver imagen 14). Para Productora, el tema de la seguridad no era problemático, por lo que las ventanas-puertas no requerían protección exterior, para las autoridades fue necesaria la colocación de rejas con motivos de greca en cada una de ellas, lo que a Productora le desagradó, no solo por lo innecesario - a decir de ellos-, sino por el desacierto estético que significa para su obra.

A un año de su inauguración, el cCC, como inversión cultural en Teotitlán del Valle, deja un escenario de subutilización, ya que se enfrentará a las condiciones presupuestales de un municipio comunitario con recursos limitados y asignados para otras necesidades en la población. Esto ya es palpable al ver las salas con exposiciones permanentes de tapetes, de la historia de la población y de sus costumbres, y simultáneamente con exposiciones itinerantes que están sujetas a la gestión cultural de los interesados, en donde predomina el letargo institucional.

También es notoria la falta de recursos para la operación del CCC, ya que por información del taller Productora, la reconocida cocinera zapoteca Abigail Mendoza es quien dirige el ccc con un grupo de mujeres, sin embargo, la participación de ellas en la operación, limpieza, y demás tareas es realizada como servicio comunitario, sin recibir remuneración alguna, a pesar de la responsabilidad familiar que ellas tienen tradicionalmente en sus hogares con la actividades de la vida cotidiana.

Pese a todo ello, el Centro Cultural Comunitario ha obtenido reconocimientos entre los cuales se encuentran: en 2017, la Medalla de Oro/Cultura en la III Bienal de Arquitectura CDMX; $1^{\text {er }}$ lugar en espacio colectivo; $2^{\circ}$ lugar en espacio colectivo (internacional); el premio especial por Edificacion Sostenible en el premio Obras Cemex; en 2018, la Medalla de Plata XV Bienal Nacional e Internacional de Arquitectura Mexicana/Cultura; el Premio Firenze Entremuros 2018 y la Medalla de Oro de la $1^{\text {a }}$ Bienal de Arquitectura Oaxaqueña 2019. Estos premios estatales, nacionales e internacionales van conformando el prestigio de las obras arquitectónicas contemporáneas, y con ello, el creciente interés de especialistas que llegan —en este caso- a 
Teotitlán del Valle. Sin embargo, los premios destacan las condiciones formales, funcionales, constructivas y contextuales desde los archivos digitales como imágenes y plantas arquitectónicas, dejando fuera de esta valoración su perfil cualitativo en el sitio para conocer la relación con las personas que trabajan ahí, o con quienes viven e interactuan con la obra desde la vida cotidiana, así como con aquellos que viajan a conocer la obra y después a conocer la población, o viceversa. Estos premios otorgados al ccc son la expresión de un fenómeno que a finales del siglo xx se analizó y denominó el efecto Guggenheim, en este caso, Teotitlán del Valle se ha incorporado a este sistema económico-cultural contemporáneo.

\section{Conclusiones}

Teotitlán del Valle, asentamiento prehispánico zapoteca del valle de Tlacolula, forma parte de un corredor histórico, cultural y turístico con aproximadamente 70 kilómetros: gastronomía, folclore, costumbres, modos de vida, sistemas de gobierno, recursos naturales y patrimonio arquitectónico desde la prehistoria hasta el siglo xx conforman el valor patrimonial de este territorio. Sin embargo, Teotitlán del Valle, como recinto de otredad, en 2016 fue objeto de una gestión exógena a cargo del taller Productora para organizar los usos arquitectónicos públicos de su centro. La construcción del Centro Cultural Comunitario - con importantes premios del gremio- denota una falta de integración comunitaria en su gestación, usos y apropiación, al mismo tiempo, la inserción arquitectónica contemporánea soslayó el valor patrimonial de Teotitlán, a expensas de construir un ícono arquitectónico. Este es un proceso unilateral en la gestión y aplicación de recursos públicos, con el objetivo de responder a las necesidades «diagnosticadas». La ponencia analiza críticamente el uso contemporáneo del patrimonio y su modificación innecesaria por la mirada interpretativa del arquitecto contemporáneo. Respondiendo al llamado de Rem Koolhaas:

debemos pensar en metodologías para un paisaje del que tarde o temprano tendremos que hacernos cargo [...] intervenir en espacios desnudos, semi-abandonados, poco poblados, en ocasiones mal conectados [...] el actual desafío de la arquitectura esta en entender el mundo rural. ${ }^{19}$

En Teotitlán del Valle, se activó acríticamente esta ideología de la acupuntura rural contemporánea.

19 Koolhaas, Rem. Congreso Cambio de Clima. 


\section{Bibliografía}

Bradomín, José María. Toponimia de Oaxaca (Crítica etimológica). Oaxaca, 1992.

Burgoa, F. Geográfica descripción, de la septentrionl, del Polo Ártico de la América. Ia edición facsimilar. Tomo I y II, de 1674. Ciudad de México: Porrúa, 1997.

Carmagnani, Marcello. El regreso de los dioses. El proceso de reconstrucción de la identidad étnica en Oaxaca, Siglos XVII y XVIII. México: Fondo de Cultura de México, 1988.

Covarrubias Salazar, Francisco, y Zárate Martínez, E. Teotitlán del Valle. Un pueblo del Valle de Tlacolula, Oaxaca. Oaxaca: UAвјо, 2007.

Esteva, Cayetano. Geografía histórica de Oaxaca. Oaxaca: GeO, 1911.

Gerhard, Peter. México en 1742. México: José Porrúa e hijos, 1962.

Koolhaas, Rem. «Apertura: cambio de clima». Congreso Cambio de Clima «arquitectura: cambio de clima». Fundación Arquitectura y Sociedad: Pamplona, España, 2016.

Lázaro, F., y Cota, E. Mercado de Artesanías. Teotitlán del valle, Oaxaca [Tesis inedita]. México: Universidad Autónoma Benito Juárez de Oaxaca, 1995.

Martínez Gracida, Manuel. «Colección de cuadros sinópticos» de los pueblos, haciendas y ranchos del estado libre y soberano de Oaxa$c a$, anexo 50. La Memoria Administrativa, presentada al H. Congreso del mismo, 17 de septiembre, 1883.

Mühlenpfordt, Eduard. Ensayo de una descripción fiel de la República de México. Con especial referencia a su geografía, etnografía y estadística. México: El estado de Oaxaca, Reimpresión de Editorial Tule, 1993.

Productora. "Centro cultural comunitario Teotitlán del Valle», 2017. Recuperado de <http://productora-df.com.mx/project/centro-cultural-comunitario-teotitlan-del-valle $>$.

Rodrigo Álvarez, Luís. Historia general del estado de Oaxaca. Puebla: Siena Editores, 2008.

Salazar, Francisco. Boletines de la Biblioteca Pública del Estado. Oaxaca, s.f.

Unesco. «Cuevas prehistóricas de Yagul y Mitla en los Valles Centrales de Oaxaca», 2017. Recuperado de <https://whc.unesco.org/es/ list/1352>. 